\title{
An eco-hydrological assessment method for temporary rivers. The Celone and Salsola rivers case study (SE, Italy)
}

\author{
Anna Maria De Girolamo ${ }^{1 *}$, Francesc Gallart ${ }^{2}$, Giuseppe Pappagallo ${ }^{1}$, Gerardina Santese ${ }^{1}$ \\ and Antonio Lo Porto ${ }^{1}$ \\ 1 Water Research Institute of the National Research Council (IRSA-CNR), Viale F. De Blasio N. 5, 70132 Bari, Italy \\ 2 Surface Hydrology and Erosion Group, Geosciences Department, Institute of Environmental Assessment and Water Research \\ (IDAEA), CSIC. Barcelona, Spain
}

Received 15 October 2013; Accepted 5 July 2014

\begin{abstract}
This paper presents the results of a study which characterizes the hydrological regime of a temporary river at reach scale and analyzes the hydrological alterations due to anthropogenic pressures using the SWAT model to estimate the daily streamflows and the periods without flow which would occur in natural conditions. The study area is the Salsola and Celone river basins, located in SE Italy. In a first part, we identified six classes of flow, the so-called Aquatic States $(A S S)$, which play a major role in determining the available mesohabitats and subsequently the characteristics of the aquatic life. The monthly occurrence of the different $A S s$ over a long period has been evaluated in order to provide useful information to design biological samplings. The results show that $d r y$ bed conditions can occur from May to January and arheic state from April to January in the reaches located in the upper part of the basin. The impacted river reaches showed a different behavior depending on the anthropogenic impacts. In a second part, two indicators based on the statistics of the periods without flows were used, monthly flow permanence and dry season predictability, for describing the flow regime components which may have been altered by anthropogenic pressures. The indexes, which were computed in impacted and natural conditions, were used as coordinates in a plot to obtain a graphical vision of the regimes. The distance between the points representing the actual (impacted) and natural states in the plot were used to classify the hydrological alterations.
\end{abstract}

Key words: Temporary rivers / hydrological regime / SWAT model / natural streamflow / hydrological status

\section{Introduction}

The flow regime is one of the drivers of the ecological status of a river, especially in temporary rivers where the characteristics of the aquatic fauna in a reach vary on time following the temporal availability of the mesohabitats driven by the occurrence and flow of water. Temporary rivers are characterized by high variability of the flow which often causes a long period of extreme low flow and the reduction of the water surface into isolated pools along the river when the flow ceases (Argyroudi et al., 2009). This results in an intermittent flow in many rivers with a shift between lotic and lentic conditions during the year which influences biotic composition (Morais et al., 2004; Buffagni et al., 2009). As a consequence biological communities may be temporally poorer in taxa and diversity than perennial rivers (Munnè and Prat, 2011).

\footnotetext{
*Corresponding author: annamaria.degirolamo@ba.irsa.cnr.it
}

The Water Framework Directive (EC, 2000), which aims at achieving at least a "good ecological and chemical quality status" for all waters, introduces the analysis of hydromorphological aspects as supporting elements in classifying the ecological status of a water body. Although temporary rivers are quite common in the Mediterranean region, the basic principle of the Water Framework Directive has been developed mostly for perennial rivers (Nikolaidis et al., 2013); whereas for temporary rivers the ecological status assessment is more difficult to define and management strategy to restore a good ecological status have to be quite specific. This has been recently pointed out by the EU "MIRAGE" Project ${ }^{1}$ (EU Project 7FP ENV 2007). Prat et al. (2014) propose a new method, the so-called "The MIRAGE tool box" for assessing

\footnotetext{
${ }^{1}$ MIRAGE (2011) is short for "Mediterranean Intermittent River ManAGEment" (see http://www.mirage-project.eu/ news.php).
} 
hydrological, ecological and physicochemical aspects in temporary rivers.

In this paper, we present the hydrological tool aimed at: (1) classifying rivers, (2) characterizing the hydrological regime at reach scale as described by Gallart et al. (2012) and (3) evaluating the hydrological alterations due to anthropogenic pressures in a temporary river. Our purpose is to give biologists an overall assessment of regime that can contribute in planning the biological samplings and provide water resource managers an easy tool which could facilitate any investigation into the effects of hydrological modifications within the biotic composition in temporary rivers. The study area is the Salsola and Celone river basin, located in SE Italy, whereas in many Mediterranean coastal areas, streamflows records are far from the natural ones due to the long-standing story of human impacts acting in the area. The SWAT model has been used to estimate the daily streamflow which would occur in natural conditions.

\section{Study area}

We applied the proposed methodology to the Salsola and Celone rivers, the two most important tributaries of the Candelaro river located in the Apulia region in Southern Italy (Fig. 1). Both the basins are characterized by a mean elevation of about $300 \mathrm{~m}$, ranging from 0 to $1100 \mathrm{~m}$. The drainage area is about 503 and $317 \mathrm{~km}^{2}$ for the Salsola and Celone, respectively. The soils texture varies from sandy-clay-loam to clay-loam or clay. The main river courses have lengths of 60 and $93 \mathrm{~km}$, respectively. The average annual precipitation in the Salsola basin is $635 \mathrm{~mm}$ and in the Celone river basin is $625 \mathrm{~mm}$. Rainfall is mostly concentrated in autumn and winter; it is unevenly distributed in space and most rainfall events are of high intensity of short duration. The main economic activity in the plain area is intensive agriculture, the main farm products being durum wheat, tomatoes, sugar beet, olives and vineyards. In the mountainous part of the basin, where the morphology is more irregular, natural and manmade forest lands and pasture are frequent. The stream flow varies rapidly and follows the precipitation regime closely. Water abstraction, point sources discharges (urban sewage) and a dam, which was built in 2000 on the Celone river, are the main hydrological pressures in the basin. Since surface water monitoring program in the study area was put into work after 1965, many of the major changes of the hydrological regimes pre-date the start of records.

\section{Material and methods}

\section{Classifying river types}

The classification of rivers is an organization of data on streams features into discrete combinations. The objectives of the classification can vary; consequently the classification can include only a general description (i.e., broad morphological characterization) or can add a

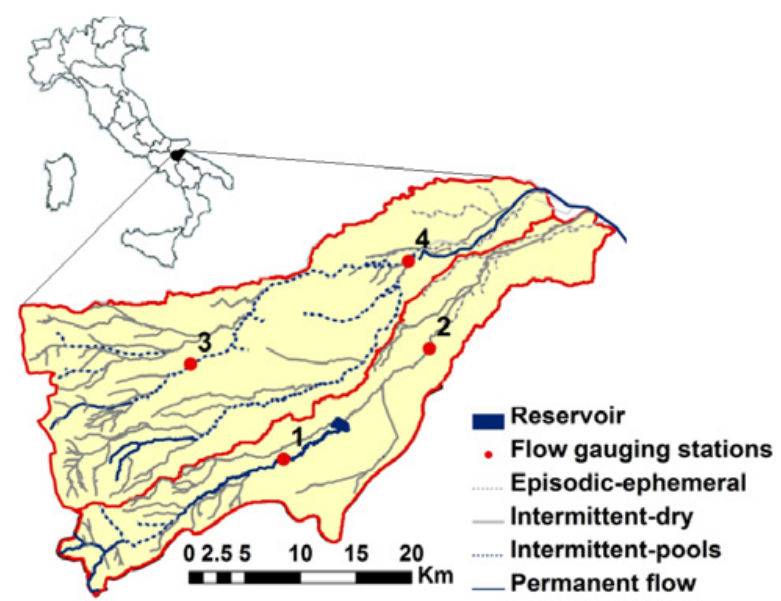

Fig. 1. Study area: Salsola and Celone river basins. River-type classification. Gauge 1 is for Celone S.V.; gauge 2 is for Celone P.te FG; gauge 3 is for Salsola Cas. and gauge 4 is for Salsola P.te FG.

more detailed reach-specific characterization such as the observed sequence of pool and riffle features.

The objective of the stream classification system used in this paper aims at assisting biologists in defining reference conditions and in determining water ecological status and help water resources managers to define watershed management guidelines dealing with flow regulation from reservoirs, water abstractions regulations and diversions.

We apply a classification based on the degree of temporariness recorded in a river reach (Table 1) according to the MIRAGE classification. In this classification, streams are classified as temporary or permanent river, and temporary rivers are differentiated in their turn in three types on the basis of the control imposed on the biological communities by the absence of flow (Gallart et al., 2012):

Intermittent pools (IP), characterized by a discontinuous flow with only pools during dry season;

Intermittent dry (ID), characterized by a lack of surface water during dry season;

Ephemeral (E), if the flow permanence is episodic.

\section{Characterizing streamflow regime}

Several authors in their studies on the ecology of temporary streams pointed out the importance of the hydrological conditions in the period during which the samples are done (Rieradevall et al., 1999; Buffagni et al., 2009; Garcia-Roger et al., 2011). Gallart et al. (2012) defined the sets of ecological relevant mesohabitats that can occur in a reach in a certain period depending on the hydrological conditions "Aquatic States" (ASs). They identified six classes of flow (ASs): Hyperrheic (flood), Eurheic (high flow), Oligorheic (continuous low flow or connected pools), Arheic (flow close to zero or disconnected pools), Hyporheic (surface water is absent, there is only hyporheic flow) and Edaphic (surface and hyporheic flow are zero). 
Table 1. Classification of stream type.

\begin{tabular}{|c|c|c|c|}
\hline Stream type ${ }^{\mathrm{a}}$ & $\begin{array}{l}\text { Flow duration } \\
\text { (months year }^{-1} \text { ) }\end{array}$ & $\begin{array}{l}\text { Pools duration } \\
\text { (months year }^{-1} \text { ) }\end{array}$ & $\begin{array}{c}\text { Dry period } \\
\text { (months year }^{-1} \text { ) }\end{array}$ \\
\hline$\overline{\text { Permanent }(\mathrm{P})}$ & $\geq 10$ & $\leq 2$ & No occurrence \\
\hline Temporary intermittent pools (IP) & $\geq 3$ & $\leq 9$ & No occurrence \\
\hline Temporary intermittent dry (ID) & $\geq 3$ & $\geq 1$ & $\geq 1$ \\
\hline Ephemeral (E) & $\leq 2$ & Variable & $\geq 10$ \\
\hline
\end{tabular}

${ }^{a}$ MIRAGE Project classification; Report D3.3.

The two last ASs are usually resumed as $d r y$ because they are characterized by the lack of surface water.

The river network of the Salsola and Celone river has been fractionated in subunits (water bodies ${ }^{2}$ ) by River Basin Authority of Puglia, following the criteria of the WFD (CIS, 2003), that identified two water bodies on each river. We tried to summarize all the ASs occurring on these reaches over a year depending on the hydrological conditions recorded over a long-time period. Monthly streamflow data recorded in gauging stations 1, 3 and 4 (from 1965 to 1996) and in the station 2 (from 2000 to 2010), were used to evaluate the statistics of occurrence of ASs. The threshold flow values between one ASs to another depend on the river bed characteristics (i.e., substratum, shape and vegetation) and they were determined using flow duration curves and through field observations.

\section{Hydrological status assessment}

The hydrological status of a reach can be defined as a measure of the divergence between Actual Status (AC) of hydrological regime, which can be altered by anthropogenic pressures, and its Natural Status (RC), which is defined as "Reference" condition.

The technique to be adopted to assess the hydrological status needs a selection of specific flow indices for describing natural flow regime components which may have been altered by anthropogenic pressures. Flow indices have to be evaluated in impacted status and in natural status to quantify the divergence between both. Because of the absence of measured flow time series long enough to account for past unimpacted situations, hydrological models can be used to estimate daily or monthly streamflow which would occur in natural conditions.

Several approaches have been developed in order to describe the flow regime, including seasonal pattern of flows, timing of extreme flows, frequency, predictability and duration of floods, droughts, daily, seasonal, and annual flow variability and rates of change (Poff et al., 1997). A large number of indices were developed in attempts to characterize different components of hydrological regime for ecological or management purpose (Richter et al., 1996). Gallart et al. (2012) identified two metrics as relevant for the qualitative status of a temporary river: the

\footnotetext{
${ }^{2}$ The Directive requires Member States to identify "water bodies" as part of the analysis of the characteristics of the river basin districts. The analysis must be reviewed, and where necessary, updated by 22 December 2013 and then every 6 years.
}

relative annual number of months with flow $\left(\mathrm{M}_{\mathrm{f}}\right)$ and the 6 months dry season predictability $\left(S d_{6}\right)$ defined by the following equation (1):

$$
S d_{6}=1-\left(\sum_{1}^{6} F d_{i} / \sum_{1}^{6} F d_{j}\right)
$$

where $F d_{i}$ is the multiannual frequency of zero-flow months for the contiguous 6 wetter months per year and $F d_{j}$ is the multiannual frequency of zero-flow months for the remaining drier 6-months. In the study area, the wetter 6-month period is December to May, whereas the drier 6-month period is June to November.

If zero-flow months occur equally throughout the year over a long period, $\mathrm{Sd}_{6}$ assumes the value 0 $\left(\sum_{1}^{6} F d_{i}=\sum_{1}^{6} F d_{i}\right.$, in equation $\left.(1)\right)$. This means that there is no clear predictability of streamflow processes.

If zero-flow months occur in the same drier 6-month period every year, $S d_{6}$ takes the value $1\left(F d_{i}=0\right.$ in equation (1)). This means that there is a high predictability. When the river is permanent, this metric cannot be calculated, we assume that $S d_{6}$ is 1 that means a fully predictability.

We selected these metrics, which are based only on the statistics of the zero-flow periods, directly $\left(\mathrm{Sd}_{6}\right)$ or indirectly $\left(\mathrm{M}_{\mathrm{f}}\right)$, because the flow interruption is considered to be the most relevant feature controlling the aquatic fauna in a temporary stream. At the same time, their use offers two advantages: firstly, flow interruption is much easier to identify than flow values when inhabitants or technicians are to be interviewed in absence or paucity of data, and secondly, the zero flow condition is also easier to model than a range of flow if the simulated threshold flow value that corresponds to an actual zero flow can be identified.

We used the two above-mentioned metrics as coordinates in a plot in order to have a graphical vision of the river types of the basin and as indicators for hydrological regime alterations. To achieve this, we evaluated the metrics in natural and impacted conditions for the studied reaches. The distance between the two points representing the actual (impacted) and natural state in the plot is used to evaluate the hydrological regime alterations. Measured streamflow data were used for calculating the metrics in impacted conditions (AC) and simulated flow values in the same river sections were used to calculate the metrics in natural conditions (RC).

\section{Modeling streamflow}

The SWAT2005 version with Arcgis interface (Winchell et al., 2007) was used in this study to simulate 
Table 2. Model input data.

\begin{tabular}{|c|c|c|c|}
\hline Variable & Origin & Scale & Method \\
\hline Precipitation & $\begin{array}{l}\text { Civil protection service } \\
\text { Puglia Reg. agency }\end{array}$ & Daily value (on basin scale) & Five rainfall stations (1990-2009) \\
\hline Temperature & $\begin{array}{l}\text { Civil protection service } \\
\text { Puglia Reg. agency }\end{array}$ & Daily value (on basin scale) & $\begin{array}{l}\text { Three temperature stations } \\
(1990-2009)\end{array}$ \\
\hline Land use map & Corine land cover 2000 EU project & ArcInfo format (scale 1:100000) & Minimum area digitalized 25 ha \\
\hline Soil map & $\begin{array}{l}\text { ACLA } 2 \text { - FEOGA EU Project } \\
\text { Consorzio per la Bonifica della Capitanata }\end{array}$ & ArcInfo format (scale 1:100000) & 31 soil profiles \\
\hline $\begin{array}{l}\text { Management } \\
\text { practices }\end{array}$ & & & $\begin{array}{l}\text { Irrigation amount, tillage oper., } \\
\text { fertilizers appl. }\end{array}$ \\
\hline Digital Elev. model & Puglia River Basin Authority & Arc Info grid format $(40 \times 40 \mathrm{~m})$ & \\
\hline WWTP discharges & Ecological police $(\mathrm{FG})$ & Average daily values & Daily discharges $\left(\mathrm{m}^{3} \cdot \mathrm{s}^{-1}\right)$ \\
\hline
\end{tabular}

streamflow in natural conditions for the selected river bodies: reach 1, 2, 3, 4 in Figure 1. The model is widely used to predict hydrological processes and the impact of point and non-point sources on waters. Many peerreviewed published articles report SWAT applications in: hydrology (Arnold and Fohrer, 2005), sediment and nutrient load assessments (Srinivasan et al., 1998), climate change impacts (Abouabdillah et al., 2010) and representation of agricultural conservation practices (Ullrich and Volk, 2009).

In a first SWAT simulation, the anthropogenic impacts actually occurring in the catchments were taken into consideration. In a second step, after calibration and validation, a new simulation without hydrological pressures was performed in order to simulate the natural streamflow. To this aim, point discharges, irrigation withdrawal and the existence of the dam were ignored. The inputs used in this work and their relative sources are summarized in Table 2. Flow discharge and pollutant load data (average daily values) from the existing WWTPs were inputted as point sources in simulating actual conditions.

The model was run on a daily time-step from January 1990 to December 2009, a time period over which only a few years of measured flow data were available. As daily wind speed and daily relative humidity were not available, the Hargreaves and Samani (1985) method was chosen to evaluate evapotranspiration; this method requires only daily maximum and minimum temperature data and is able to produce realistic results for semiarid areas. The SCS Curve Number Method (USD-Soil Conservation Service, 1972) was selected to calculate surface runoff, since only daily rainfall values were available for the study area. The Salsola was divided into 18 sub-basins, and the Celone into 9 sub-basins. Prior to calibration, the sensitivity analysis (SA) developed by van Griensven et al. (2002) was conducted for 27 parameters to assess the most sensitive hydrological parameters that can influence river flow. The SA was then carried out using streamflow simulation at the Salsola P.te FG (gauge 4, in Fig. 1) and at the Celone S.V. (gauge 1, in Fig. 1) for the period 1990-1992. Among the most sensitive parameters are soil depth $(\mathrm{z}(\mathrm{mm}))$, curve number $(\mathrm{CN})$, threshold depth of water in the shallow aquifer for return flow (GW_QMIN (mm)), antecedent soil water content (SOL_AWC $\left(\mathrm{mm} \mathrm{H}_{2} \mathrm{O} / \mathrm{mm}\right.$ soil)), soil evaporation compensation factor (ESCO) and surface runoff lag time (days). An initial manual calibration was performed working with the above-mentioned parameters influencing surface flow and baseflow in order to have a smaller range of parameters than the initial range. After this step, the Sequential Uncertainty Fitting version 2 (SUFI 2) procedure (Abbaspour et al., 2007), included in the SWAT-CUP software (http://www. neprashtechnology.ca/), was applied to perform the uncertainty analysis.

\section{Results}

\section{River-type classification}

Figure 1 shows a map which is a first attempt to classify the river reaches following the MIRAGE classification of stream types. It was defined using measured streamflow data recorded from 1965 to 1996 in streamflow gauging stations 1, 3 and 4 and from 2000 to 2010 in the gauge 2 and we also verified the flow and pools duration through farmers' interviews. Most of the reaches are classified as Intermittent Pool (IP) or Intermittent Dry (ID) type. This classification, which refers to the impacted status, might change from year to year due to a great inter-annual variability in hydrological regime that is recorded in the study area. Hence, a water body which is defined in the long term as an IP river can show a hydrological gradient from permanent to ID during 1-year period.

\section{Streamflow regime: AS}

Differences in ASs can be observed along the river network at the same date. Figure 2 shows some typical ASs which occur in the study area (Celone river, reach 1).

We evaluated the patterns of occurrence of ASs of some sites located in the vicinity of the gauging stations $1,2,3$ and 4. We fixed the threshold values between one class of flow and another before calculating the frequency of occurrence of each ASs. In particular, we used the flow 

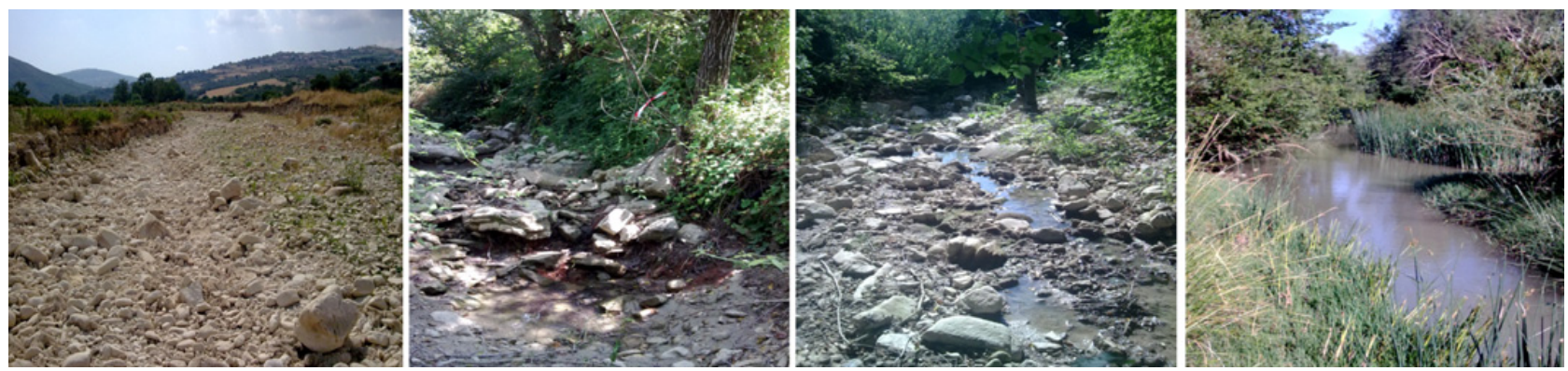

Fig. 2. Typical aquatic states of the Celone river: (a) Edaphic; (b) Arheic; (c) Oligorheic; (d) Eurheic.

duration curve (Fig. 3) for selecting the minimum flow for Hyperrheic and Eurheic status $110 \%$ of exceedance of frequency and point of inflection in the curve, respectively). The other thresholds were fixed through field observations (Table 3). The threshold values relate to gauging station 2 (Celone river) located downstream the reservoir are assumed to be the same as station 1, located upstream. The measures of the extreme low flow in this section were not available because the Celone river was dry during the study period (2010). Once the flow thresholds were evaluated, the relative monthly frequencies of occurrence of the different ASs were evaluated; aquatic states frequency graphs (ASFGs), Figures 4 and 5, show the results. Buffagni et al. (2009) and Munnè and Prat (2009, 2011) pointed out that in temporary rivers biological sampling need to be adapted to the temporal patterns of ASs (available sets of mesohabitats) because biological communities may be temporally poorer in taxa and diversity than perennial rivers. Thus, the ASFG graphs on the one hand give an overall of regime assessment and on the other hand contribute in planning the biological samplings. The frequencies of occurrence of the ASs are more or less the same for the reaches located in the upper part of the basin (Fig. 4, gauge 3; Fig. 5, gauge 1). The graphs show a high frequency of $d r y$ and Arheic (disconnected pools) states recorded from July to November. This means that ecological samplings have to be planned taking into account the fact that from January to April the reach goes through high flow conditions, whereas from May to December flow conditions vary from year to year. However, as Reach 1 shows a high frequency of occurrence of $d r y$ status ( $>50 \%$ ) from July to October, samplings should be planned before and after these dates.

Reach 4, located in the plain area, is generally permanent even if Dry and Oligorheic (connected pools) states might occur from June to September (Fig. 4(b)). Its natural regime changes on account of wastewater discharges. Reach 2 was completely dry from July to December in the study period from 2000 to 2010 , after the building of the reservoir (Fig. 5(b)).

\section{Model calibration}

The performance of the model simulations was evaluated using the Nash and Sutcliffe efficiency (NSE)

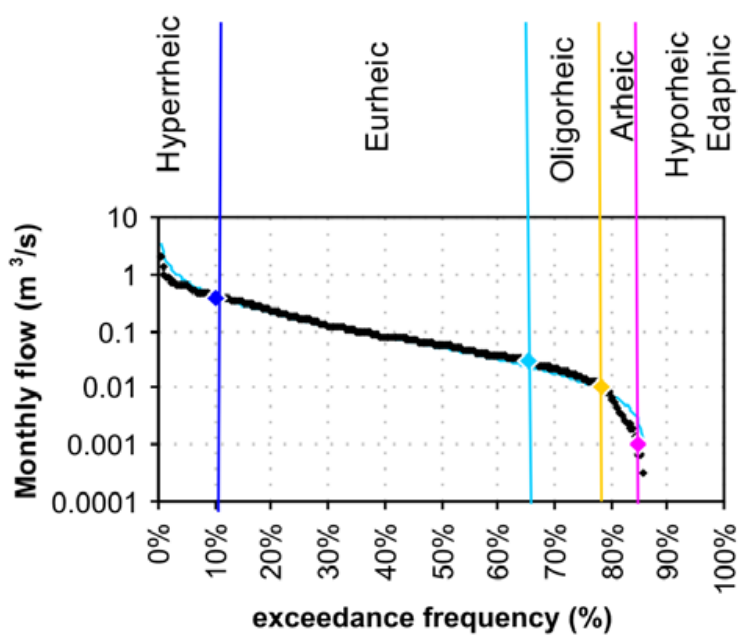

Fig. 3. Flow duration curve of measured data from 1965 to 1991 , and thresholds for the diverse quantitative classes of flow at gauge 3 (Salsola Cas.). The line shows the lognormal distribution of measured flow data.

(Nash and Sutcliffe, 1970) and correlation coefficient $\left(R^{2}\right)$. The model was calibrated over the period 1990-92 (Fig. 6), the NSE values at the Salsola P.te FG (gauge 4) and Celone S.V. (gauge 1) were 0.56 and 0.61 , respectively, whereas the $R^{2}$ values were 0.75 and 0.88 . In the validation period (1995-1996) NSE was 0.58 and 0.41 and $R^{2}$ was 0.78 and 0.77 at the Salsola P.te FG (4) and Celone S.V. (1) gauges, respectively. The parameters, their range and the calibrated values are summarized in Table 4. It is well known that watershed models suffer from uncertainty in predictions from model structures, input data and parameters (Refsgaard et al., 2007). Uhlenbrook et al. (1999) pointed out that the effects of the model and parameter uncertainties were larger for low-flow conditions than for the flood events.

The SUFI-2 procedure, included in the SWAT-CUP software, was used to perform calibration and uncertainty analysis. The coefficient of determination $R^{2}$ multiplied by the coefficient of the regression line was used as objective function $\left(b R^{2}\right)$. As Figure 7 shows, the observed streamflow and the "best simulation" for unimpacted conditions were compared with the $95 \%$ prediction uncertainty (95PPU) for a reach (Salsola P.te FG, gauge 4) and a large uncertainty interval during the dry period. Hence, 
Table 3. Thresholds values between different Aquatic States (ASs) for the Celone and Salsola rivers.

\begin{tabular}{|c|c|c|c|c|c|c|c|c|}
\hline \multirow{2}{*}{ Min. flow for } & \multicolumn{4}{|c|}{ Celone river } & \multicolumn{4}{|c|}{ Salsola river } \\
\hline & \multicolumn{2}{|c|}{ Gauge 1} & \multicolumn{2}{|c|}{ Gauge 2} & \multicolumn{2}{|c|}{ Gauge 3} & \multicolumn{2}{|c|}{ Gauge 4} \\
\hline$\overline{\text { Hyperrheic (flood) }}$ & $>1.600$ & $10 \%$ & $>2.100$ & $10 \%$ & $>0.400$ & $10 \%$ & $>4.000$ & $10 \%$ \\
\hline Oligorheic (conn. pools) & $>0.010$ & $67 \%$ & $>0.010$ & $50 \%$ & $>0.008$ & $80 \%$ & $>0.015$ & $95 \%$ \\
\hline Arheic (disc. pools) & $>0.001$ & $76 \%$ & $>0.001$ & $61 \%$ & $>0.001$ & $86 \%$ & $>0.002$ & $98 \%$ \\
\hline Hyporheic-edaphic (dry) & $<0.001$ & & & & $<0.001$ & & $<0.002$ & \\
\hline
\end{tabular}
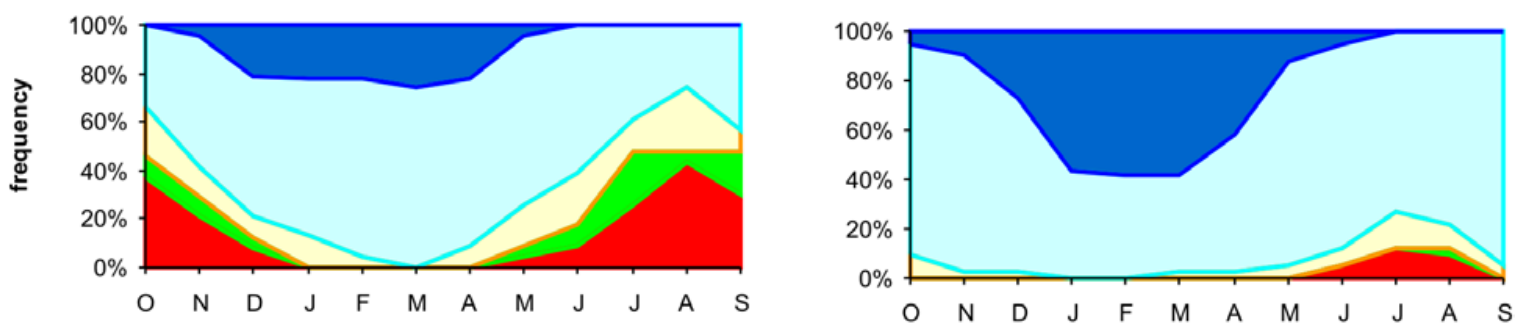

Hyporeic $\square$ Arheic $\square$ Oligorheic $\square$ Eurheic $\square$ Hyperrheic

Fig. 4. Aquatic states frequency graph for the gauging stations 3 and 4, Salsola river.
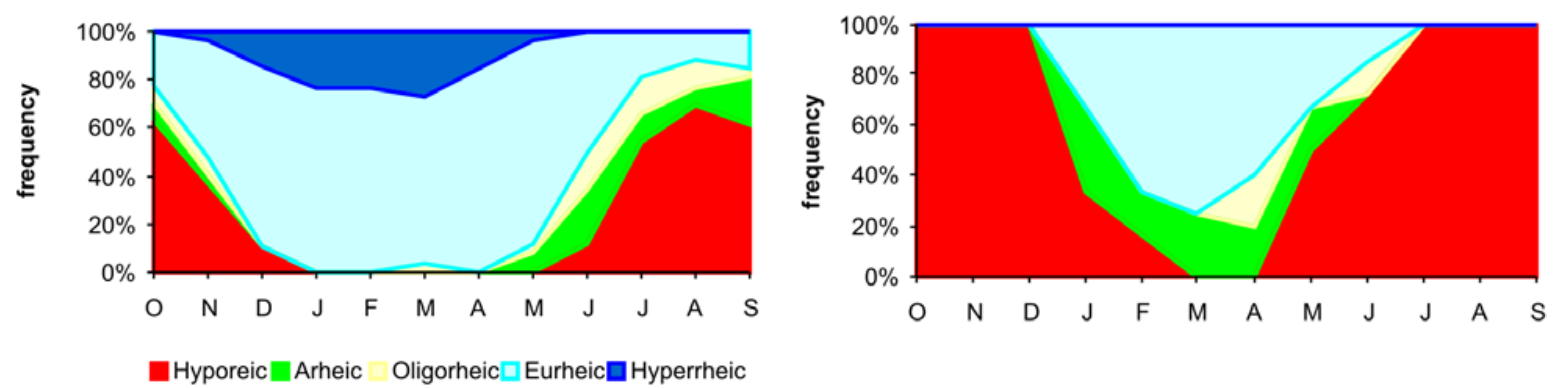

Fig. 5. Aquatic states frequency graph for the gauging stations 1 and 2, Celone river.

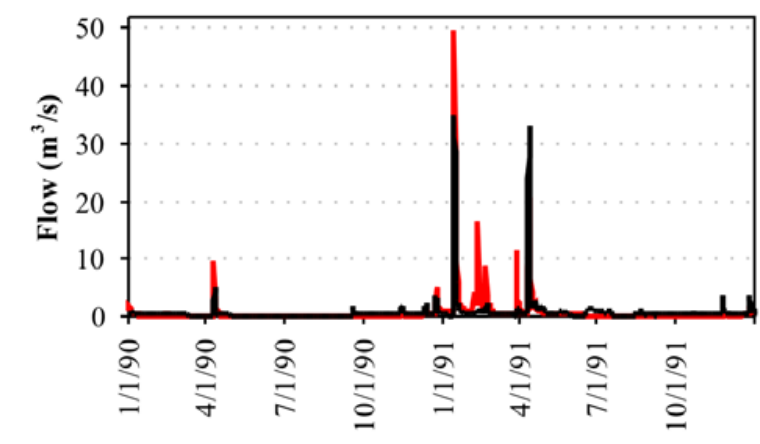

gauge 4

Observed

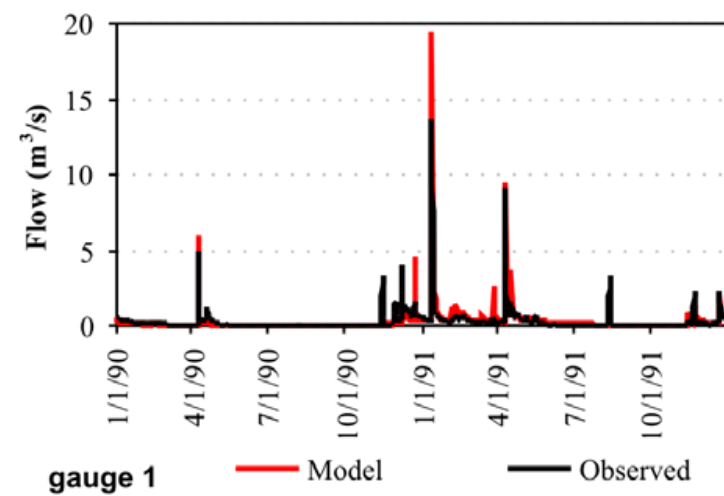

Fig. 6. Measured and simulated streamflow at the Salsola P.te FG (gauge 4) and Celone S.V. (gauge 1). Calibration (1990-91).

the simulation of low flow may be a weak point in the predictability of the SWAT model. Generally, a discrepancy between measured and simulated flow is recorded in temporary rivers where extreme low-flow conditions tend to be overestimated by most hydrological models (Kirkby et al., 2011).

In the present work, the "no-flow" condition is a key point in the metric calculations; thus, it is critically important to understand if the extreme low-flow conditions predicted by the SWAT model are realistic or not. If predicted extreme low flow in the "best simulation" is not zero in those reaches which are recognized as temporary streams, a correction of flow series is needed before calculating the metrics. We called "Zero Flow" threshold the simulated streamflow value that corresponds to actual dry conditions (no flow) in a reach. This value is specific 
Table 4. SWAT parameters, their range and the calibrated values.

\begin{tabular}{|c|c|c|c|c|}
\hline$\overline{\text { Parameter }}$ & Rank & Description & Actual value used & Range \\
\hline Sol_Z & 1 & Soil depth (mm) & $150-500^{\mathrm{a}}$ & $0-3500$ \\
\hline $\mathrm{CN}$ & 2 & SCS curve number & $54-88^{\mathrm{a}}$ & $35-98$ \\
\hline GWQMN & 3 & $\begin{array}{l}\text { Threshold depth of water in the shallow aquifer } \\
\text { required for return flow to occur }\left(\mathrm{mm} \mathrm{H}_{2} \mathrm{O}\right)\end{array}$ & $0-10^{\mathrm{b}}$ & $0-5000$ \\
\hline Canmx & 4 & Maximum canopy storage $(\mathrm{mm})$ & $3-7^{\mathrm{a}}$ & $0-100$ \\
\hline SOL_AWC & 5 & Available water capacity $\left(\mathrm{mm} \mathrm{H}_{2} \mathrm{O} / \mathrm{mm}\right.$ soil) & $0.08-0.16^{\mathrm{a}}$ & $0-1$ \\
\hline $\mathrm{ESCO}$ & 6 & Soil evaporation compensation factor & 0.35 & $0-1$ \\
\hline BLAI & 7 & Maximum potential leaf area index $\left(\mathrm{m}^{2} / \mathrm{m}^{2}\right)$ & $1.25-5$ & $0.5-10$ \\
\hline SURLAG & 8 & Surface runoff lag coefficient (days) & 7 & $0-10$ \\
\hline GWREVAP & 9 & Revap coefficient & 0.2 & $0.02-0.2$ \\
\hline ALFA_BF & 10 & Baseflow alfa factor (days) & $0.37-0.9^{\mathrm{b}}$ & $0-1$ \\
\hline
\end{tabular}

${ }^{a}$ Value varies according to input data (soil, land use).

${ }^{\mathrm{b}}$ Value was adapted in sub-basins depending on their location: Monti Dauni (upstream stations 1, 3), Tavoliere (downstream 1, 3).

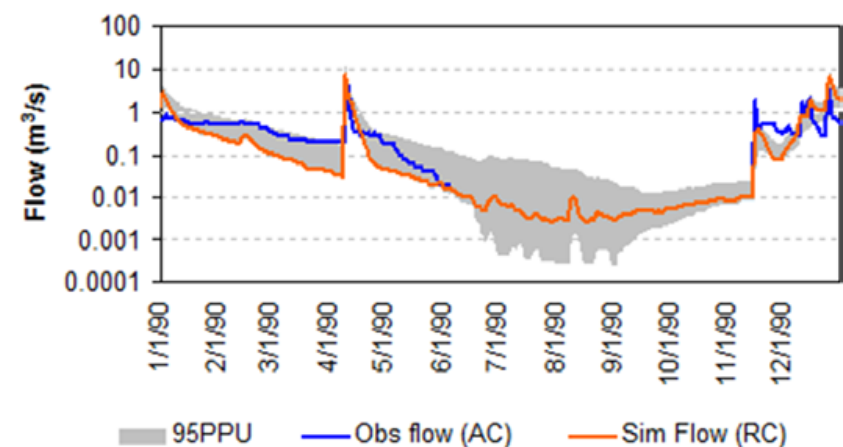

Fig. 7. Observed streamflow (AC), simulated streamflow (RC) and the $95 \%$ uncertainty predictions (P-Factor $=0.28$; RFactor $=0.20$ ) for the driest year (1990) on recorded at the Salsola P.te FG (gauge 4).

for each river section depending on the local conditions such as geology, hydraulic conductivity and river bed permeability, transmission losses and channel width, in addition to the intrinsic limits of the hydrological model used for the simulations. In order to define these thresholds for the study river reaches, we selected one of the driest summers recorded in the past (1990) during which the river network was dry all over, we verified this condition through interviews with farmers, and for each river section we assumed the extreme low flow value simulated by the model in that period as zero flow threshold. The values are: $0.004 \mathrm{~m}^{3} . \mathrm{s}^{-1}$ (gauge 3 ); $0.011 \mathrm{~m}^{3} . \mathrm{s}^{-1}$ (gauge 4); $0.055 \mathrm{~m}^{3} \cdot \mathrm{s}^{-1}$ (gauge 1); $0.065 \mathrm{~m}^{3} \cdot \mathrm{s}^{-1}$ (gauge 2).

\section{Hydrological status}

We represented the hydrological regime of reaches 1 , 2, 3 and 4 in the temporary stream regime (TSR) plot as points using the metrics as coordinates, both in actual (impacted) and natural streamflow conditions (Fig. 8). From mathematical point of view, the dependent variable $\left(S d_{6}\right)$ changes with the independent variable but there is an area (blue triangle) in the plot (Fig. 8) where the metric values are incompatible (i.e., if $\mathrm{M}_{\mathrm{f}}$ takes the value 0.4 , as a result of equation (1), $\mathrm{Sd}_{6}$ cannot assume values higher

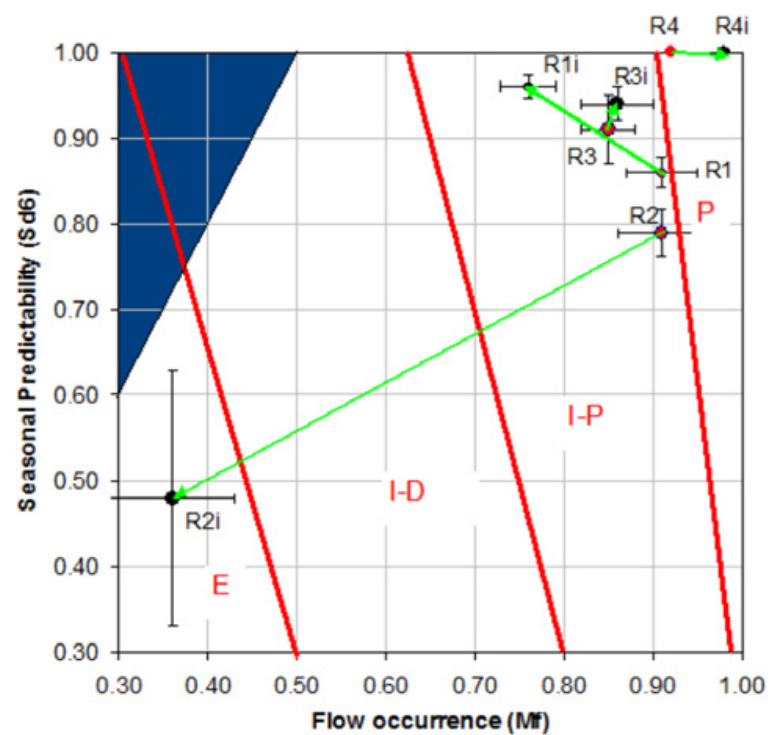

Fig. 8. Plot of interannual $\mathrm{Sd}_{6}$ versus $\mathrm{M}_{\mathrm{f}}$ metrics in actual (black points) and natural conditions (red points). Error bars show the standard error. Blue triangle shows the area where the metrics are incompatible. The red lines show an approximate separation between the regime types.

than 0.8). The red lines used in the plot to differentiate the river types are fixed after analyzing data recorded in several streams in Mediterranean area (Gallart et al., 2012).

The distance between the corresponding points in unimpacted and impacted conditions is an indicator of the hydrological regime alterations capturing a shift in flow permanence and dry season predictability. The points representing the river reach $R 1$ and $R 2$ in natural conditions are located on the right in the graph and when we calculate the metrics using measured data, which include the impacts (water abstractions and reservoir), the points move from the right to the left $(R 1 i$ and $R 2 i)$. This means that a reduction in flow occurrence $\left(\mathrm{M}_{\mathrm{f}}\right)$ was recorded in the actual status. In this work, we differentiate only "critical" and "non-critical" flow status alterations, according as the river segment has changed its original classification or not. Hence, the hydrological alterations are critical for reach 2, which was classified as an IP river 
in natural conditions while became $\mathrm{E}$ after the dam was built.

Reach 3 and reach 4 move from the left to the right. In fact, inlet discharges which are higher than water abstractions changed their natural regime toward more permanent conditions. For these river reaches anthropogenic impacts might have a huge influence on water quality modifying chemical and physical parameter such as temperature, $\mathrm{pH}, \mathrm{BOD}_{5}, \mathrm{O} 2 \mathrm{~N}-\mathrm{NO}_{3}, \mathrm{~N}-\mathrm{NH}_{4}$ and $\mathrm{P}_{-} \mathrm{PO}_{4}$. As a consequence, the autochthonous species may be substituted by other which can be invasive or of lower ecological value.

\section{Discussion}

Characterization of surface water body types is an important step in the WFD implementation process. The main objective is to define sets of streams that are comparable in order to define reference conditions. The directive proposes a classification based on the ecoregions (Illies, 1978) and two systems A and B. System A uses fixed categories of three factors to classify rivers: altitude, basin size and geology of the river basin. System B uses descriptors such as: distance from river sources, energy of flow, mean water slope and river discharge which determine the structure and composition of the biological communities of the watercourses. However, several authors are convinced that local conditions might be more correlated with biological habitats than with catchment conditions (Nerbonne and Vondracek, 2001). Munnè and Prat (2004) suggest a second level of classification based on geology and flow regime. The classification proposed in MIRAGE Project (Prat et al., 2014) and tested in this work is based on local conditions of streamflow. It differentiates the reaches where the flow can be not continuous in ID and IP and E. In ID and IP rivers, biological communities are similar to those of permanent rivers during the wet season, while when the flow is scarce and only pools remain along the streams an impoverishment of biological communities can occur. Hence, the biological sampling can be done with the same methodology used in permanent rivers but needs to be adapted to the hydrological regime. In E streams water flow is occasional and pools are short lived, here some resilient or colonizing organisms can be found but an advanced community development is impossible. Hence, for these streams new sampling methodologies are needed in order to classify their ecological status.

The graphs ASFGs show the frequency of occurrence of the ASs in a reach over a long-time period. This is a general information about the hydrological regime in a river section that is useful to design the calendar of samplings. While, in order to understand the relationship between the hydrological regime and communities development for giving a correct interpretation of biological samplings it should be studied the ASs occurred few months before biological samplings.
In the present paper, we also tested a method to evaluate hydrological status of a reach which is easier than the most common approaches used to evaluate the degree of alteration of a stream (Richter et al., 1996). Because in temporary rivers the most ecologically relevant metrics are flow permanence and the predictability of the dry season (Gallart et al., 2012; De Girolamo et al., 2014), the proposed approach analyzes the changes occurring in these factors only. On the other hand, a preliminary analysis of hydrological pressures in the study area suggests that variation in the low-flow component are supposed in all the water bodies, while no relevant modification are expected in the high-flow component, in timing, rate and frequency of change in flow conditions in the majority of reaches.

A critical step in the procedure is the identification of the thresholds between the different degrees of alteration. Here we identified hydrological alteration as "critical" when a transition of hydrological class occurs. However, further studies are needed determining the relationship between flow alteration and ecological response in order to define more detailed hydrological alteration classes.

We used the SWAT model to evaluate natural streamflow. The model requires a lot of data and is time consuming, but on the other hand it offers the possibility of simulating both hydrological processes (in natural or impacted conditions) and the impact of point and nonpoint sources on waters. Although, a general problem in watershed modeling still to be solved is the common lack of measured data to calibrate and validate the model performances (De Girolamo and Lo Porto, 2012), hydrological models can be a valid support in many different phases of the WFD implementation process. The results of the present work demonstrate that the SWAT model was able to predict hydrological processes; although extreme low-flow conditions can constitute a critical point in modeling streamflow, the method applied made possible the use of qualitative observations made by the inhabitants to solve this point. Since the objective of this work is to identify significant differences in hydrological status between natural and actual conditions, it is important to quantify accurately the differences that could arise from model performance and those differences which derive from anthropogenic impacts. This is a difficult task whose successful accomplishment requires both an analysis of anthropogenic hydrological pressures and an accurate uncertainty analysis of the low-flow simulation in addition to field observations.

\section{Conclusions}

In this paper, we tested an approach aiming at supporting the ecological quality assessment of temporary streams. The research deals with three different aspects which are relevant for supporting the assessment of the Ecological Status: river-type classifications, analysis of the different sets of mesohabitats which can occur in a reach in a certain period (ASs) and Hydrological Status 
(divergence of actual regime from its natural condition). The main conclusions drawn are as follows:

The classification of the river reaches regimes based on the occurrence of the different mesohabitat sets has proved to be a valuable operational tool that helps biologists in selecting the sampling strategy in order to define the ecological status. For river reaches classified as IP and ID samplings have to be adapted to the hydrological regime.

The approach proposed in the present work to evaluate hydrological status is a fast way to identify river reaches in critical hydrological conditions. The method which analyzes only the changes occurring in two factors (flow permanence and dry seasonal predictability) compares the metrics in actual and natural states. If critical hydrological conditions take place, a further analysis could be carried out which includes the changes in other components of streamflow regime depending on anthropogenic pressures.

The classification of hydrological alterations is a fundamental step in designing a Program of Measures for water quality restoration of a river. The results of this work show that further studies are needed to formulate the relationship between hydrological alterations and ecological response in order to define the thresholds of hydrological impact acceptability.

Acknowledgements. This research was supported by European Community's Seventh Framework Programme, FP7/2007-2011, MIRAGE Project (Contract no. 211732). The authors gratefully acknowledge G. Amoruso from the Puglia Civil Protection Service and G. Niro from Consorzio per la Bonifica della Capitanata for providing data. The authors are indebted to A. Calabrese who collaborated in field activities. We are grateful to N. Prat for sharing constructive discussions. Thanks are also to the reviewers for their valuable scientific comments and recommendations.

\section{References}

Abbaspour K.C., Yang J., Maximov I., Siber R., Bogner K., Mieleitner J., Zobrist J. and Srinivasan R., 2007. Spatiallydistributed modelling of hydrology and water quality in the prealpine/alpine Thur watershed using SWAT. J. Hydrol., 333, 413-430.

Abouabdillah A., Oueslati O., De Girolamo A.M. and Lo Porto A., 2010. Modeling the impact of climate change in a Mediterranean catchment (Merguellil, Tunisia). Fresen. Environ. Bull., 19(10a), 2334-2347.

Argyroudi A., Chatzinikolaou Y., Poirazidis K. and Lazaridou M., 2009. Do intermittent and ephemeral Mediterranean rivers belong to the same river type? Aquat. Ecol., 43, 465476.

Arnold J.G. and Fohrer N., 2005. SWAT2000: current capabilities and research opportunities in applied watershed modeling. Hydrol. Process., 19(3), 563-572.

Buffagni A., Armanini D.G. and Erba S., 2009. Does lentic-lotic character of rivers affect invertebrate metrics used in the assessment of ecological quality? J. Limnol., 68, 95-109.
CIS, 2003. Common Implementation Strategy for the Water Framework Directive (2000/60/EC). River and lakes typology, reference conditions and classification systems. Guidance document No. 10. Luxenbourg, Lu, Office for Official Publications of the European Community.

De Girolamo A.M. and Lo Porto A., 2012. Land use scenario development as a tool for watershed management within the Rio Mannu Basin. Land Use Policy, 29, 691-701.

De Girolamo A.M., Lo Porto A., Pappagallo G., Tzoraki O. and Gallart F., 2014. The hydrological status concept. Application at a temporary river (Candelaro, Italy). River Res. Appl. doi: 10.1002/rra.2786.

EC, 2000. Directive 2000/60/EC of the European Parliament and the Council Directive establishing a framework for community action in the field of water policy. Off. J. Eur. Commun., Brussels, 22/12/2000, L. 327, 1-72.

Gallart F., Prat N., García-Roger E.M., Latron J., Rieradevall M., Llorens P., Barberá G.G., Brito D., De Girolamo A.M., Lo Porto A., Buffagni A., Erba S., Neves R., Nikolaidis N.P., Perrin J.L., Querner E.P., Quiñonero J.M., Tournoud M.G., Tzoraki O., Skoukulidis N., Gomez R., Sanchez-Montoya M.M. and Froebrich J., 2012. A novel approach to analysing the regimes of temporary streams in relation to their controls on the composition and structure of aquatic biota. Hydrol. Earth Syst. Sci., 16, 1-18.

Garcia-Roger E.M., Sanchez-Montoya M.M., Gomez R., Suarez M.L., Vidal-Abarca M.R., Rieradevall M., Latron J. and Prat N., 2011. Do seasonal changes in habitat features influence aquatic macroinvertebrate assemblages in permanent vs temporary Mediterranean streams? Aquat. Sci., 73, $567-579$.

Hargreaves G.H. and Samani Z.A., 1985. Reference crop evapotranspiration from temperature. Appl. Eng. Agric., 1, 96-99.

Illies J., 1978. Limnofauna Europaea, Gustav Fisher, Verlag, Stuttgart, $532 \mathrm{p}$.

Kirkby M.J., Gallart F., Kjeldsen T.R., Irvine B.J., Froebrich J., Lo Porto A., De Girolamo A. and the MIRAGE team, 2011. Classifying low flow hydrological regimes at a regional scale. Hydrol. Earth Syst. Sci., 15, 3741-3750.

MIRAGE Project Deliverable D3.3., 2011. Characterization of hydrological conditions at catchment scale, classification of hydrological regimes. http://www.mirage-project.eu/ index.php

Morais M., Pinto P., Guilherme P., Rosado J. and Antunes I., 2004. Assessment of temporary streams: the robustness of metric and multimetric indices under different hydrological conditions. Hydrobiologia, 516, 229-249.

Munné A. and Prat N., 2004. Defining river types in a Mediterranean area: a methodology for the implementation of the EU Water Framework Directive. Environ. Manage., 33, 1-19.

Munné A. and Prat N., 2009. Use of macroinvertebrate-based multimetric indices for water quality evaluation in Spanish Mediterranean rivers: an intercalibration approach with the IBMWP index. Hydrobiologia, 628, 203-225.

Munné A. and Prat N., 2011. Effects of Mediterranean climate annual variability on stream biological quality assessment using macroinvertebrate communities. Ecol. Ind., 11, 651662.

Nash J.E. and Sutcliffe J.V., 1970. River flow forecasting through conceptual models. J. Hydrol., 10, 282-290. 
Nerbonne B.A. and Vondracek B., 2001. Effects of local land use on physical habitat, benthic macroinvertebrates, and fish in the Whitewater River, Minnesota, USA. Environ. Manage., 28(1), 87-99.

Nikolaidis N.P., Demetropoulou L., Froebrich J., Jacobs C., Gallart F., Prat N., Lo Porto A., Campana C., Papadoulakis V., Skoulikidis N., Davy T., Bidoglio G., Bouraoui F., Kirby M., Tournoud M.G., Polesello S., Barberá G.G., Cooper D., Gomez R., SanchezMontoya M.M., Latron J., De Girolamo A.M. and Perrin J.L., 2013. Towards a sustainable management of Mediterranean river basins. Policy recommendations on management aspects of temporary river basins. Water Policy, 15, 830-849.

Poff N.L., Allan J.D., Bain M.B., Karr J.R., Prestegaard K.L., Richter B.D., Sparks R.E. and Stromberg J.C., 1997. The natural flow regime. Bioscience, 47, 769-784.

Prat N., Gallart F., Von Schiller D., Polesello S., GarcíaRoger E.M., Latron J., Rieradevall M., Llorens P., Barberá G.G., Brito D., De Girolamo A.M., Lo Porto A., Buffagni A., Erba S., Nikolaidis N. P., Querner E.P., Tournoud M.G., Tzoraki O., Skoulikidis N., Gómez R., Sánchez-Montoya M.M., Tockner K. and Froebrich J., 2014. The MIRAGE Toolbox: an integrated assessment tool for temporary streams. River Res. Appl., doi: 10.1002/ rra.

Refsgaard J.C., van der Sluijs P.J., Højberg A.L. and Vanrolleghem P.A., 2007. Uncertainty in the environmental modelling process - A framework and guidance. Environ. Modell. Softw., 22(11), 1543-1556.
Richter B.D., Baumgartner J.V., Powell J. and Braun D.P., 1996. A method for assessing hydrologic alteration within ecosystems. Conserv. Biol., 10, 1163-1174.

Rieradevall M., Bonada N. and Prat N., 1999. Community structure and water quality in Mediterranean streams of a Natural Park (Sant Llorenç de Munt, NE Spain). Limnetica, 17, 45-56.

Srinivasan R., Ramanarayanan T.S., Arnold J.G. and Bednarz S.T., 1998. Large area hydrologic modelling and assessment part II: model application. J. Am. Water Resour. Assoc., 34(1), 91-101.

Uhlenbrook S., Seibert J., Leibundgut C. and Rodhe A., 1999. Prediction uncertainty of conceptual rainfall-runoff models caused by problems to identify model parameters and structure. Hydrol. Sci. J., 44(5), 279-299.

Ullrich A. and Volk M., 2009. Application of the soil and water assessment tool (SWAT) to predict the impact of alternative management practices on water quality and quantity. Agric. Water Manage., 96(8), 1207-1217.

USD-Soil Conservation Service (SCS), 1972. National engineering handbook. In: Section 4 Hydrology, USD-Soil Conservation Service (SCS), Washington, DC, U.S. Government Printing Office, 4-10.

Van Griensven A., Francos A. and Bauwens W., 2002. Sensitivity analysis and auto-calibration of an integral dynamic model for river water quality. Water Sci. Technol., 45(9), 325-332.

Winchell M., Srinivasan R., Di Luzio M. and Arnold J., 2007. ArcSWAT Interface for SWAT 2005 - User's Guide, Blackland Research Center, Temple, TX. 